\title{
Assessment of water quality in distribution networks through the lens of disinfection by-product rules
}

\author{
Nilufar Islam ${ }^{1}$, Rehan Sadiq $^{1 *}$, Manuel J. Rodriguez ${ }^{2}$ and Christelle Legay ${ }^{2}$ \\ 'School of Engineering, University of British Columbia Okanagan Campus, 1137 Alumni Avenue, Kelowna, BC Canada V1V $1 V 7$ \\ 2École supérieure d'aménagement du territoire et de développement régional, Université Laval, Canada
}

\begin{abstract}
Disinfection with chlorine is a common practice to ensure secured drinking water, but results in potentially harmful disinfection by-products (DBPs), when excess chlorination is done. The US Environmental Protection Agency (US EPA) has established Stage 1 and Stage 2 disinfection by-product Rules (DBP rules) to control DBP exposure. A modified version of the Canadian Council of Ministries of the Environment water quality index (CCME WQI) is used to assess water quality. CCME WQI is a globally accepted index to assess water quality, but is too generic to be used for DBP rules. The study developed a scheme to make the index suitable for DBP rules. A scoring method based on an analytic hierarchy process (AHP) is applied to assign weights based on DBP rules. A previously modified CCME WQI (Islam et al., 2014) is adapted along with the weights to perform the assessment at the distribution network (DN). A case study was performed on 7 sampling stations in a Québec City DN. The spatial water quality variations are presented using kriging - a geostatistical method, which identifies the regions with relatively poor water quality and highlights the potential locations for re-chlorination points. The proposed assessment formulation is flexible to handle situations with limited data, which makes it especially suited to smaller municipalities.
\end{abstract}

Keywords: CCME water quality index, Stage 1 DBP Rule, Stage 2 DBP Rule, chlorination

\section{INTRODUCTION}

Chlorination at the treatment plant and distribution network $(\mathrm{DN})$ is a common practice to ensure safe drinking water. This provides detectable levels of free residual chlorine (FRC), which is useful to control biofilm growth; however it generates undesirable disinfection by-products (DBPs) (Charisiadis et al., 2015; Rook, 1974) when excess chlorination is done. Many of the DBPs are potentially harmful and have certain negative effects on human health (Richardson et al., 2007). In the United States there are a number of water quality regulations that directly or indirectly address issues related to DBPs, e.g., the Stage 1 and Stage 2 Rules (USEPA, 2005). The first regulation, 'Total trihalomethane rule', was introduced in 1979 (USEPA, 2005). Stage 1 and Stage 2 DBP Rules (henceforth referred to as DBP rules) were implemented in 1998 and 2006, respectively. These regulations are focused on the control of DBP exposure by providing various parameter thresholds, such as maximum contaminant level (MCL) and maximum contaminant level goals (MCLG). Therefore, water quality assessment needs to be done based on these parameter thresholds, from the perspective of:

- Microbiological water quality that can be degraded by inadequate chlorination

- Chemical water quality that can be compromised by DBPs

- Aesthetic water quality (taste and odours) that can be unacceptable due to high levels of chlorination

Many water quality assessment formulations have been proposed to assess surface water (Liou et al., 2004; Pesce and Wunderlin, 2000; Said et al., 2004; Swamee and Tyagi, 2007). These studies have used an index based on water quality parameters for specific

\footnotetext{
* To whom all correspondence should be addressed.

e-mail: rehan.sadiq@ubc.ca

Received: 20 March 2015; accepted in revised form 17 March 2016
}

usage. The Canadian Council of Ministries of the Environment water quality index (CCME WQI) is a globally accepted index to represent complex water quality data from a regulatory perspective. It has been applied to source water and needs to be applied for DNs (Khan et al. 2003). Previously, there was some limitation in the CCME WQI formulation and some modifications were made to overcome this (Islam et al., 2013). However, the index is too generic and requires further modification to make it suitable for DBP rules. For example, careful parameter selection is needed for DBP rules. There should also be weights among the parameters, which is missing from the CCME WQI. The proposed formulation is flexible enough to incorporate limited data, which makes it suitable for small municipalities which experience frequent 'boiled water' advisories. Such municipalities also have limited resources and expertise to assess water quality. Moreover, after waterborne contamination related episodes like Walkerton (2000), and North Battleford (2001), in Canada, smaller communities in Canada have gained more attention from the Government. Suitable water quality assessment formulations can help in this regard by enabling intelligent decision-making based on the results and the implementation of appropriate management strategies.

The objective of this study was to develop a suitable formulation to assess water quality within DNs in the context of DBP rules. The next section provides a brief background required to establish the assessment formulation, followed by information on model development. A case study on a DN of Québec City (Province of Québec, Canada) is then discussed. Finally, conclusions and recommendations are provided.

\section{BACKGROUND}

\section{Stage 1 and 2 DBP Rules}

The purpose of Stage 1 and 2 DBP Rules (DBP rules) is to improve public health protection by controlling population exposure to DBPs. A water supply system where water is treated 
with a disinfectant (e.g., chlorine, chloramine) other than UV light should follow the Stage 2 DBP Rule. This final rule recommends meeting MCLs as an average at a compliance monitoring location, rather than an average for the whole system. There are many DBPs; however, the Stage 1 and 2 DPB Rules concentrate on two groups of DBPs: trihalomethanes (THMs) and haloacetic acids (HAAs). Total trihalomethanes (TTHM ) includes 4 species, such as chloroform, bromodichloromethane (BDCM), dibromochloromethane (DBCM), and bromoform. Haloacetic acids (HAAs) generally include 5 species (called HAA5), e.g., monochloroacetic acid (MCAA), dichloroacetic acid (DCAA), trichloroacetic acid (TCAA), monobromoacetic acid (MBAA), and dibromoacetic acid (DBAA). TTHM and HAA5 are the most important groups among the DBPs as the regulations have set MCLs for both of them. There are some MCLGs for some individual DBPs; however, these are not equally discussed and stressed in DBP rules. Table 1 provides the MCL and MCLG for some of the parameters stated in the DBP rules (USEPA, 2010).

These rules state that the maximum residual disinfectant level (MRDL) for disinfectant residuals such as FRC are $4 \mathrm{mg} / \mathrm{L}$ (USEPA, 2006) (Table 1). However, taste and odour problems due to high levels of FRC depend on personal sensitivity. For example, the WHO (2004) suggests a range of FRC concentrations from 0.2 to $4 \mathrm{mg} / \mathrm{L}$, but Australian Guidelines suggest a threshold level of $0.6 \mathrm{mg} / \mathrm{L}$ (Health Canada, 2009). In summary, a lower level or no FRC represents the possibility of microbiological contamination and a higher level can generate more DBPs. It should be noted that the Stage 2 DBP Rule is always coupled with the Long Term 2 Enhanced Surface Water Treatment Rule (USEPA, 2007) to notify users of risk trade-offs between DBPs and pathogens, for which MCL for turbidity can be used as it is a surrogate measure of microbiological water quality (USEPA, 2009). Table 1 states the threshold values (MCL, MCLG, and MRDL) for the parameters stated in the DBP rules (USEPA, 2009). Maintaining these thresholds (e.g., MCL and MCLG) for some parameters can help in assessing the water quality in DNs.

\section{Water quality assessment}

Water quality can be assessed based on selected water quality parameters. One of the common practices is to select specific usage-related parameters and convert these to a unitless measure, called a water quality index (WQI). The WQI integrates complex information such as temporal parameter values and aids decision making. Three basic steps are established to assess the water quality:

- Selecting appropriate parameters based on usage

- Converting selected parameters to unitless sub-indices

- Applying appropriate aggregation formulation to estimate the WQI

Appropriate parameter selection is dependent upon the intended use of water, and should be free from redundancy. The parameter values are then converted to unitless subindices, as parameters may have different units, representative of different situations. For example, a lower value of any DBP is desirable, while FRC should be in between a certain range to represent the desirable water quality. Therefore, a transformation is required to convert parameter values to a sub-index value between $[0,1]$, where 1 represents the best quality and 0 represents the worst quality. The final step is the aggregation of the sub-indices, where common aggregation functions such as unweighted average, weighted average, root sum power additive, unweighted harmonic square mean, unweighted multiplication, weighted multiplication, geometric mean, maximum-minimum and other complex formulations are used (Boyacioglu, 2007; Dunnette, 1979; Espejo et al., 2012; Hurley et al., 2012; Islam et al., 2011; Liou et al., 2004; Pesce and Wunderlin, 2000; Swamee and Tyagi, 2007). Most of the formulations have fixed parameters, which makes the WQI rigid and not suitable for DBBP rules.

CCME WQI was determined to be the most accepted WQI as it is flexible enough to include any parameter, simplistic, and reflects regulatory violations (Islam et al., 2013). However, it has

\begin{tabular}{|l|c|c|c|c|}
\hline \multicolumn{5}{|c|}{ Regulatory maximum contaminant level (MCL) and maximum contaminant level goals (MCLG) for DBPs and related } \\
parameters (USEPA, 2010)
\end{tabular}

${ }^{*}$ USEPA (2009a) states 1 NTU when the system uses conventional or direct filtration and $5 N T U$ when the system uses filtration other than the conventional or direct filtration.

** The maximum residual disinfection levels (MRDLs) 
some redundancy in factor consideration and has been modified in one of our previous studies (Islam et al., 2013).

The CCME WQI is a popular index consisting of 3 factors (CCME, 2001):

- $\quad$ Scope $\left(F_{1}\right)$

- Frequency $\left(F_{2}\right)$

- Amplitude $\left(F_{3}\right)$

The final aggregation formulation is a form of root sum power additive function such as (CCME, 2001):

$$
\mathrm{CCME} \mathrm{WQI}=100-\left(\frac{\sqrt{F_{1}^{2}+F_{2}^{2}+F_{3}^{2}}}{1.732}\right)
$$

The percentage of total number of failed parameters is called scope $\left(F_{1}\right)$, while the percentage of regulatory violations for all samples is called frequency $\left(F_{2}\right)$. The amount of violation is measured by the factor named amplitude $\left(F_{3}\right)$. The constant 1.732 is a normalization factor used to render the CCME WQI as a value from 0 to 100 . The formulation can become more sensitive if water quality parameters' relative weights are incorporated. Assigning weights will make the formulation expert-dependent as often expert judgements is used in this regard (Espejo et al., 2012). Hurley et al. (2012) have assigned relative weights among the factors $F_{1}, F_{2}$ and $F_{3}$, instead of among the water quality parameters. Espejo et al. (2012) proposed a scheme to assign weights among the parameters by placing the parameters at different levels. However, this study was not specified for DBP rules.

\section{PROPOSED METHODOLOGY}

The methodology to assess the water quality based on DBP rules is stated in Fig. 1, which contains 7 steps: (1) water quality parameter selection, (2) converting parameters to sub-indices, (3) generating parameter relative weights, (4) aggregating sub-indices to get the modified CCME WQI, (5) temporal and spatial analyses of a DN, (6) comparing with other WQI formulations, and (7) analysing sensitivity by increasing the number of parameters.

\section{Parameter selection}

DBP rules highlight some parameters related to DBPs (Table 1); TTHM, HAA5, and FRC are parameters that can represent the chemical water quality associated with DBPs. Other DBPs can also be considered based on data availability. In order to represent the microbial water quality, turbidity can be incorporated (USEPA, 2009). Additionally, total organic carbon (TOC) can be considered if available. The DBP rules highlight the role of TOC as a precursor for generating DBPs. All of these parameters can contribute towards chemical and microbial water quality from the perspective of DBP rules. It should be noted that only the most significant parameters should be selected to avoid redundancy. In small municipalities, TTHM, FRC, and turbidity may be the only available parameters, and were thus considered for this study. However, additional DBPs (BDCM, DBCM, and DCAA) were also added at a later stage to assess the effect of parameter addition on the sensitivity of the index.

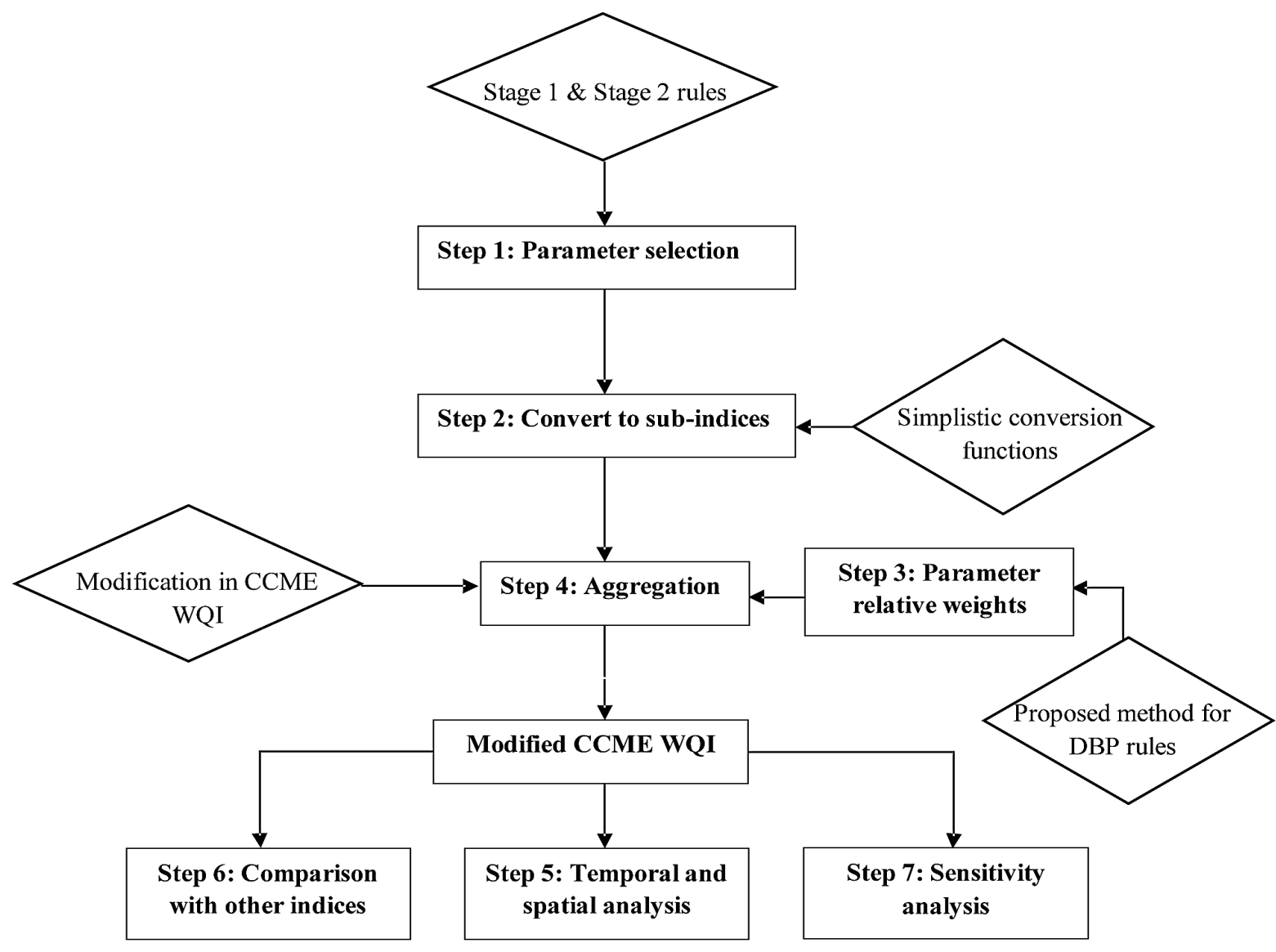

Figure 1:

Methodology to assess water quality (diamond shape gives the applied approach to performing a particular step). 


\section{Conversion to sub-indices}

Based on the nature of the parameter selected, two types of sub-index functions are assigned: (i) increasing, and (ii) optimal (Fig. 2). The original CCME WQI has linear normalization, while calculating the $F_{3}$ factor (CCME, 2001). Incorporating more breakpoints (denoted as points in Fig. 2) inside the transformation function, instead of using the linear function, can increase the sensitivity.

The increasing sub-index function is applicable for parameters (e.g. TTHM and turbidity) for which an increasing value is undesirable. The transformation function can contain 2,3 , or even 4 break points (Fig. 2a) based on the decision-makers' preference. For TTHM and turbidity, 4 point functions are used for this study.

The optimal sub-index is valid for parameters (e.g FRC) for which an optimal range of values is desirable to achieve the intended water quality. Figure $2 \mathrm{~b}$ illustrates different options for the optimal sub-index function. This can be composed of 2-2, 2-3, 3-2 or 3-3 break points. The 3-3 break point function is used for FRC in this study.

The sub-index functions used for this study are stated in detail in Table 2 . The functions are carefully constructed based on the MCL stated in Table 1. However, the transformation functions are flexible and can be modified by the decision maker by changing the break points.

\section{Assignment of weights}

In this study, a new methodology based on various multicriteria decision-making methods has been proposed to assign parameter weights based on DBP rules. Firstly, 4 criteria are selected named as 'type of parameter', 'strength posed

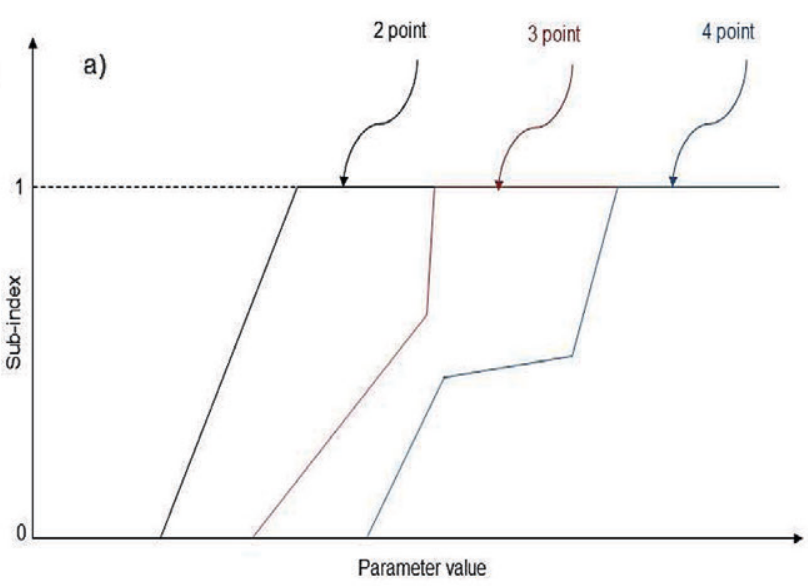

b)

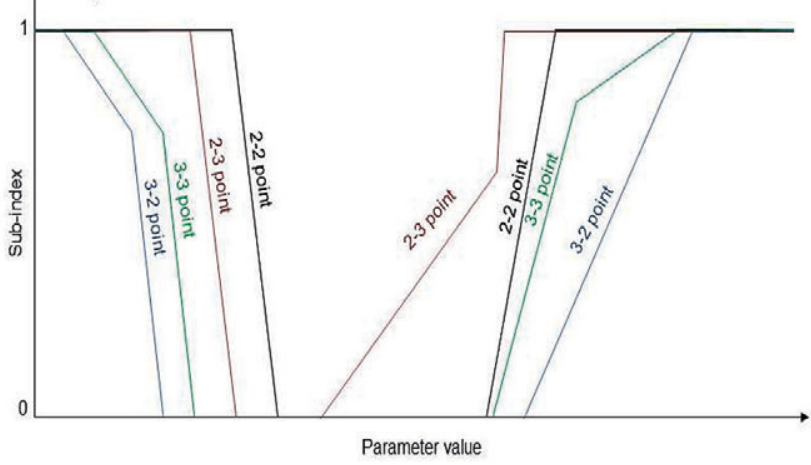

Figure 2:

Proposed sub-index function: (a) increasing, and (b) optimal

\begin{tabular}{|c|c|c|c|c|}
\hline \multicolumn{5}{|c|}{$\begin{array}{c}\text { TABLE } 2 \\
\text { Sub-index (SI) functions }\end{array}$} \\
\hline $\begin{array}{l}\text { Parameter } \\
\text { name }\end{array}$ & $\begin{array}{l}\text { Function } \\
\text { name }\end{array}$ & Mathematical representation & Graphical representation & \\
\hline Turbidity & Increasing & $\begin{array}{l}\text { If Turb }=0, \mathrm{SI}_{\text {Turb }}=0 \\
\text { If } 0<\text { Turb }<0.1 \mathrm{NTU}, \mathrm{SI}_{\text {Turb }}=0.5 \text { Turb } \\
\text { If } 0.1 \mathrm{NTU}<\text { Turb }<0.5 \mathrm{NTU}, \mathrm{SI}_{\text {Turb }}=0.05+\frac{17(\text { Turb }-0.1)}{8} \\
\text { If } 0.5 \mathrm{NTU}<\text { Turb }<1 \mathrm{NTU}, \mathrm{SI}_{\text {Turb }}=0.9+2 \text { (Turb-0.5) } \\
\text { If Turb }>1 \mathrm{NTU}, \text { SITurb=1 }\end{array}$ & Turb. NTU & $\Delta$ \\
\hline TTHM & Increasing & 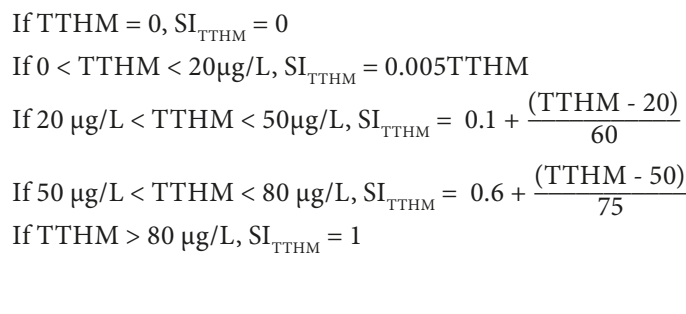 & 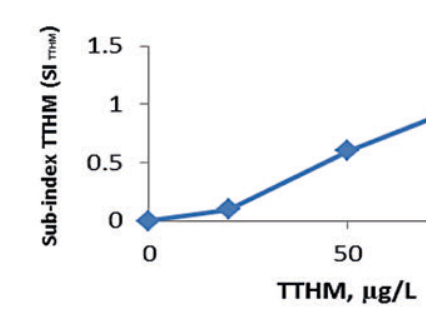 & 100 \\
\hline FRC & Optimal & $\begin{array}{l}\text { If } \mathrm{FRC}=0, \mathrm{SI}_{\mathrm{FRC}}=0 \\
\text { If } 0<\mathrm{FRC}<0.15 \mathrm{mg} / \mathrm{L}, \mathrm{SI}_{\mathrm{FRC}}=1-\frac{100 \mathrm{FRC}}{12} \\
\text { If } 0.15 \mathrm{mg} / \mathrm{L}<\mathrm{FRC}<0.2 \mathrm{mg} / \mathrm{L}, \mathrm{SI}_{\mathrm{FRC}}=0.2-4(\mathrm{FRC}-0.15) \\
\text { If } 0.2 \mathrm{mg} / \mathrm{L}<\mathrm{FRC}<0.8 \mathrm{mg} / \mathrm{L}, \mathrm{SI}_{\mathrm{FRC}}=0 \\
\text { If } 0.8 \mathrm{mg} / \mathrm{L}<\mathrm{FRC}<0.9 \mathrm{mg} / \mathrm{L}, \mathrm{SI}_{\mathrm{FRC}}=8(\mathrm{FRC}-0.8) \\
\text { If } 0.9 \mathrm{mg} / \mathrm{L}<\mathrm{FRC}<1 \mathrm{mg} / \mathrm{L}, \mathrm{SI}_{\mathrm{FRC}}=0.8+2(\mathrm{FRC}-0.9) \\
\text { If } \mathrm{FRC}>1 \mathrm{mg} / \mathrm{L}, \mathrm{SI}_{\mathrm{FRC}}=1\end{array}$ & 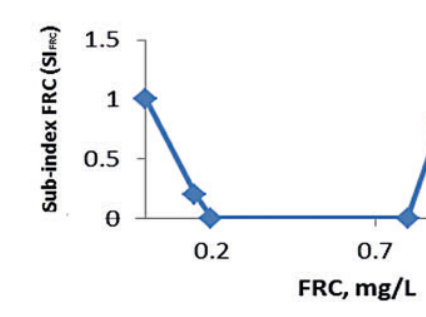 & 1.2 \\
\hline
\end{tabular}


by regulation', 'Stage 1/2 DBP threshold related', and 'risk related'. There are sub-criteria under each criterion except Criteria 4. A score between 0 and 10 is suggested under each sub-criterion. Table 3 summarizes the sub-criteria and their scoring. For example, for Criterion 1 (type of parameter) subcriteria are:

- Microbe (M) related: A score of 10 will be assigned when the parameter is a direct or indirect measure of microbes.

- DBP related: Any DBP species will get a score of 10 .

- Partially M and DBP related: Any operational parameter related to M and DBP will receive a score of 8 .

- Precursor: DBP related precursors will get a score of 5 .

Scoring for Criterion 2 is done based on the strength posed by the regulations. The parameters that have MCLs are given higher scores than the parameters with MCLGs or parameters without any stated thresholds (Table 3). Criterion 3 is based on the frequency of mention of a particular parameter in the Stage 1 and Stage 2 Rules. For example, parameters which have MCL/ MCLG mentioned in both Stage 1 and Stage 2 Rules receive higher scores than the parameters which are only mentioned in the Stage 2 Rule. As controlling risk exposure is one of the main aims of the Stage 2 DBP Rule, a $4^{\text {th }}$ criterion was considered based on the possible cancer risk due to oral and inhalation exposure. An exposure study (Sadiq and Rodriguez, 2004b)chloramine, and ozone react with organic matter in water. Chlorine being the most common disinfectant used in the drinking water industry worldwide, significant attention has been focused on chlorinated DBPs. A new indexing method using fuzzy synthetic evaluation is proposed to determine the health risk associated with the two major groups of chlorinated DBPs--trihalomethanes (THMs

TABLE 3

Sub-criteria with scores for estimating parameter weights

\begin{tabular}{|l|l|c|}
\hline \multicolumn{2}{|c|}{ Criteria 1: Type of parameter } & Score \\
\hline Sub-criteria & Brief explanation & 10 \\
\hline Microbes (M) related & Directly or indirectly related to microbes. & 10 \\
\hline DBP related & Directly measured DBPs & 8 \\
\hline Partially M \& DBP related & Microbial and DBP related operational parameter & 5 \\
\hline Precursor & DBP related precursors & \\
\hline
\end{tabular}

Criteria 2: Strength posed by regulation

\begin{tabular}{|l|l|c|}
\hline Sub-criteria & Brief explanation & Score \\
\hline MCL based & Has direct MCL & 10 \\
\hline MCLG based & Has MCLG to maintain MCLs for others & 6 \\
\hline Mentioned in DBP rules & Mentioned in DBP rules but without any specific MCLG or MCL & 2 \\
\hline Not mentioned & Not mentioned in DBP rules & 0 \\
\hline \multicolumn{1}{|c|}{ Criteria 3: Stage 1/2 DBP threshold related } & Score \\
\hline Sub-criteria & Brief explanation & 6 \\
\hline Thresholds are available only in Stage 2 DBP rule & New MCLG available in Stage 2 DBP rule & 10 \\
\hline Thresholds are mentioned both in Stage 1 \& 2 DBP rules & MCLG available in Stage 1 and stage 2 DBPs & 0 \\
\hline No threshold is available in DBP rules & & 0 \\
\hline
\end{tabular}

Criteria 4: Risk related (cancer)

\begin{tabular}{|c|c|c|}
\hline Parameter name & $\begin{array}{l}\text { Scoring method adapted from Sadiq \& Rodriguez } \\
(2004) \text { with updated value from IRIS data base }\end{array}$ & Score* \\
\hline Chloroform & 0.000 & 2 \\
\hline BDCM & 0.230 & 8 \\
\hline DBCM & 0.307 & 10 \\
\hline Bromoform & 0.029 & 1 \\
\hline DCAA & 0.179 & 6 \\
\hline TCAA & 0.255 & 9 \\
\hline TTHM & 0.566 & 10 \\
\hline HAA5 & 0.434 & 8 \\
\hline Other DBPs & & 2 \\
\hline Not a DBP & & 0 \\
\hline
\end{tabular}

${ }^{*}$ Oral ingestion only. There was no data available for some of the DBPs, therefore, score value 2 is assumed. 
suggested an approach for assigning relative weights among DBPs. The study used the IRIS (Integrated Risk Information System) database to gather the unit risk values for oral and inhalation exposure. Later, the unit risk values were normalized to assign relative weights among DBPs. The same approach was used, but based only on oral ingestion, using updated values from IRIS (USEPA, 2013). However, the weights are again normalized from $0-10$. Based on the abovementioned methodology, a score is assigned for each of the 14 parameters given in Table 1. $S_{i j}$ can be the denotation of the score where $i$ represents the order of the parameter and $j$ is the criteria order. The summary of these scores can be seen in Table 4 .

Later, four criteria are compared with each other using an analytic hierarchy process (AHP), a mathematical technique (Saaty, 1977) providing the weights for each parameter related to an issue. Pair-wise comparison is the basis of AHP and estimates the priority vector of the contributing parameters. For example, Table 5 presents the pairwise comparison between Criteria 1, Criteria 2, Criteria 3, and Criteria 4. The table also shows the AHP calculation steps. The first column in Table 5 shows individual pair-wise comparisons between Criteria 1 and Criteria 1, Criteria 2, Criteria 3 and Criteria 4. Criteria 2, Criteria 3 and Criteria 4 are 5,3 , and 2 times more important than Criteria 1, respectively. In the same way, cell values are assigned for each column. Geometric means were calculated for each row and finally the relative weight for each criterion was normalized based on the summation of these geometric means. The summation of these relative weights in a particular family is equal to 1 . Calculation details can be seen in Table 5 and interested readers are referred to other studies for details (Chung and Lee, 2009; Tesfamariam and Sadiq, 2006). Criteria relative weights are denoted by $W_{\mathrm{j}}$, where $j$ is the criteria order. $W_{j}$ (denoted as $W_{1}, W_{2}, W_{3}$, and $W_{4}$ for 4 criteria) is obtained using AHP and summarized in Table 4.

Finally, the parameter weights $\left(P_{\mathrm{i}}\right)$ can be estimated using the scores $\left(S_{\mathrm{i}, \mathrm{j}}\right)$ and the criteria relative weights $\left(W_{\mathrm{j}}\right)$ by using the following formulation:

$$
P_{i}=\frac{\sum_{j=1}^{j=j} S_{i, j} W_{j}}{\operatorname{Max}\left(\sum_{j=1}^{j=j} S_{i, j} W_{j}\right)}
$$

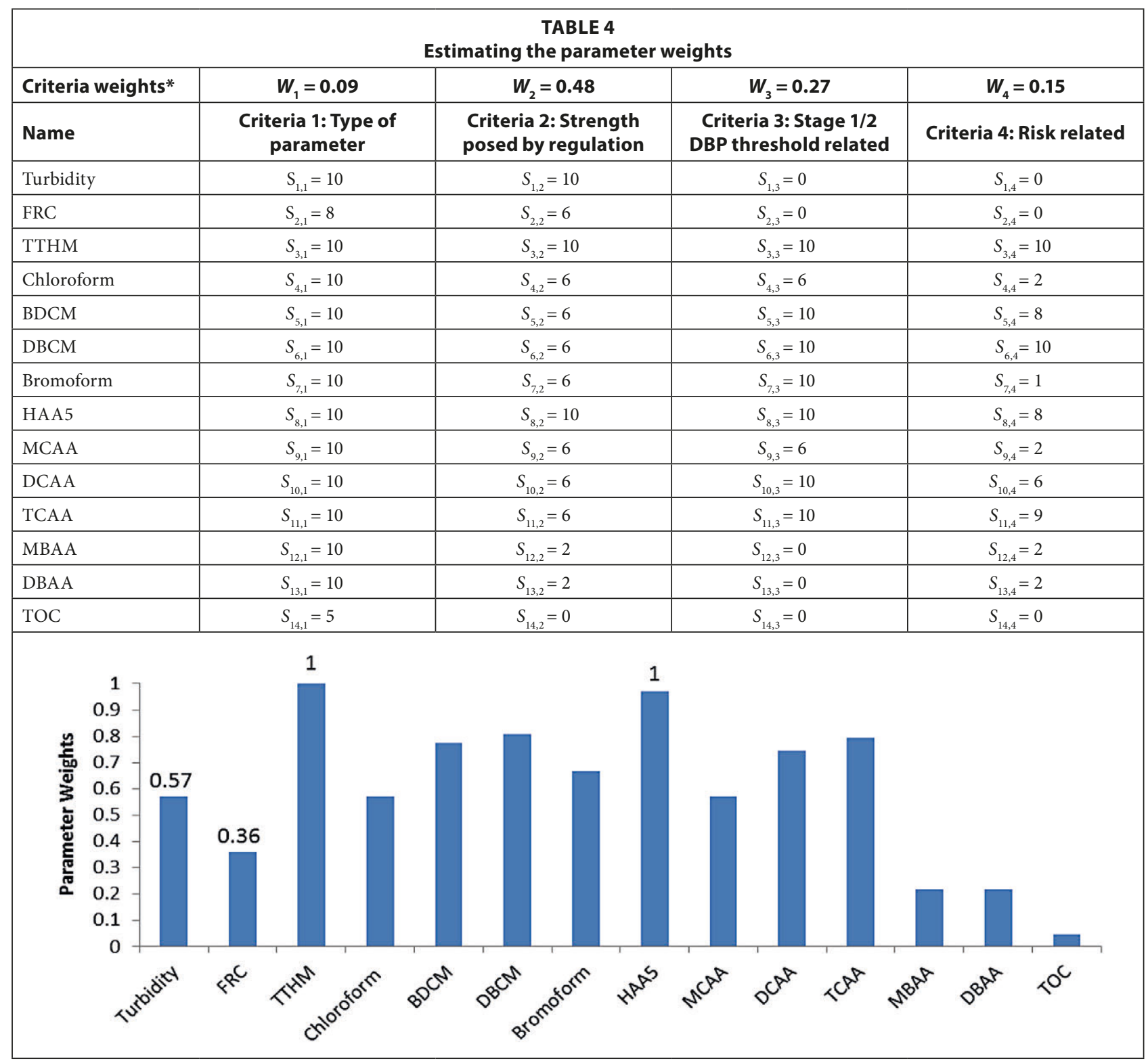

${ }^{\star}$ Estimated using AHP (analytic hierarchy process); $S=$ scores assigned from Table 3 


\section{Aggregation}

Finally, the modified CCME WQI aggregation is done using the following modification:

Scope, $V_{1}$ : The percentage of failed parameters is modified using the relative weights of the parameters.

$$
V_{1}=\frac{\Sigma P_{i} \times G}{\Sigma P_{i}}
$$

where: $C$ is a count factor of 1 or 0 . If one parameter fails $C=1$, otherwise $C=0$.

Frequency and amplitude, $V_{2}$ : Islam et al. (2013) have combined frequency and amplitude. Another modification is done by combining the relative weights for the normalized sum of excursions (nse):

$$
\mathrm{nse}=\frac{\sum_{i=1}^{n} \mathrm{SI}_{i, k} \times P_{i}}{\sum_{i=1}^{n} P_{i}}
$$

where: SI = sub-index value; $i=$ order of parameter; $k=$ order for each time step; $P=$ relative weight.

$$
\begin{aligned}
& V_{2}=\frac{\mathrm{nse}}{0.005 \mathrm{nse}+0.005} \\
& \text { Modified CCME WQI }=100-\frac{\sqrt{V_{1}^{2}+V_{2}^{2}}}{1.414}
\end{aligned}
$$

The value should be from 0 to 100 , where we can define the water quality as [0-20] poor; [21-50] marginal; [51-70] fair; [71-80] good; [81-90] very good; and [91-100] excellent (Islam et al., 2013).

\section{WATER QUALITY ASSESSMENT: A CASE STUDY}

\section{Study area}

Water quality is assessed for a DN in Québec City, province of Québec, Canada. The area serves around 240000 inhabitants. St. Charles Lake is the source of the water, which is refined by a set of treatments, e.g., sieving, flocculation, sedimentation, filtration, intermediate ozonation, and chlorination (Legay et al., 2011). Re-chlorination is also applied at some locations in the system. The sampling programme extended from April 2006 to April 2008, with monthly sampling at 7 sampling points (Fig. 3), named SP1, SP2, SP3, SP4, SP5, SP6 and SP7. Sampling points SP1, SP2, and SP3 are designated as re-chlorination points.

\section{Sampling and analytical methods}

Samples were collected between 9.00 and 11.00. The tap water was allowed to run for $5 \mathrm{~min}$ before taking the sample. Collected samples were analysed for FRC and turbidity. Several DBPs were also analysed; however, only TTHM (summation of chloroform, BDCM, DBCM, and bromoform) was considered for this study. Later, DCAA was added to observe the effect of an additional parameter on the index. Samples were collected in $40 \mathrm{~mL}$ vials for TTHM and DCAA. Dechlorinating agent, ammonium chloride, was added to the vials before collecting the samples. For turbidity and FRC, samples were collected in $125 \mathrm{~mL}$ plastic bottles. Samples were stored in the laboratory at $4^{\circ} \mathrm{C}$ directly after collection. FRC was measured in situ using a Hach colorimeter (model DR-820) and a titrimetric method (Standard Methods 4500-Cl G). A turbidimeter (Hach, model 2100N) was used for turbidity measurement. Gas chromatography with mass spectroscopy detection (GC-MS) (Varian chromatograph, model 3900) was used to measure TTHM. US EPA method 524.2 (USEPA, 1995a) was adapted to conduct the analysis. Detection limits for the TTHM species, i.e., chloroform, BDCM, DBCM, and bromoform were $0.3,0.3,0.4$ and $0.5 \mu \mathrm{g} / \mathrm{L}$, respectively. A gas chromatography with electron capture detector (GC-ECD) (Perkin Elmer chromatograph, model AutoSystem XL) was used to analyse DCAA using USEPA method 552.2 (USEPA 1995b). The detection limit for DCAA was $0.9 \mu \mathrm{g} / \mathrm{L}$.

\section{Monthly water quality assessment}

The scoring method using AHP, as explained earlier, was used to assign weights to the parameters. TTHM and HAA5 came out as the parameters with relatively higher weights (Table 4). They were ranked highly as they are regulated strongly with MCLs, have higher exposure risk, and are prominent in the regulations. The proposed WQI is formulated based on, firstly, chemical (considering only DBPs) and, secondly, microbial water quality; therefore, a microbial parameter such as turbidity is given a moderate weighting of 0.57 (out of 1). FRC is one of the common parameters, but is indirectly related to microbial and chemical water quality, and received a weighting of 0.36 . The rest of the parameter weights can be seen in Table 4.

The proposed water quality assessment was conducted using only turbidity, FRC and TTHM. These are also commonly available parameters in smaller municipalities. Figure 4 shows the monthly water quality index variation for 7 sampling points. Sampling points SP4, SP6, and SP7 show a relatively unchanged water quality index compared to other points. Significant monthly variation can be seen for SP2 and SP3. The water quality index is relatively higher in winter (January to April) and starts degrading during summer (May to August). The temperature during summer is high, which increases the reaction rate of chlorine which thus forms more DBPs. FRC is also expected to degrade as it reacts with organic and inorganic compounds. Mostly, the water quality

\begin{tabular}{|c|c|c|c|c|c|c|}
\hline & Criteria 1, A & Criteria 2, B & Criteria 3, C & Criteria 4, D & $\begin{array}{c}\text { Geometric Mean, } \\
G=(A \times B \times C \times D) 1 / 4\end{array}$ & $\mathbf{W j}=\mathbf{G} / \mathbf{S}$ \\
\hline Criteria 1, A & 1.00 & 0.20 & 0.33 & 0.50 & 0.43 & 0.09 \\
\hline Criteria 2, B & 5.00 & 1.00 & 2.00 & 3.00 & 2.34 & 0.48 \\
\hline Criteria 3, C & 3.00 & 0.50 & 1.00 & 2.00 & 1.32 & 0.27 \\
\hline Criteria 4, D & 2.00 & 0.33 & 0.50 & 1.00 & 0.76 & 0.16 \\
\hline \multicolumn{5}{|l|}{ Summation, S } & 4.84 & \\
\hline
\end{tabular}
reached its lowest levels in the autumn season (September to

\section{TABLE 5}

Estimating criteria relative weight, $\mathrm{W}_{\mathrm{j}}$ using analytical hierarchy process (AHP) 


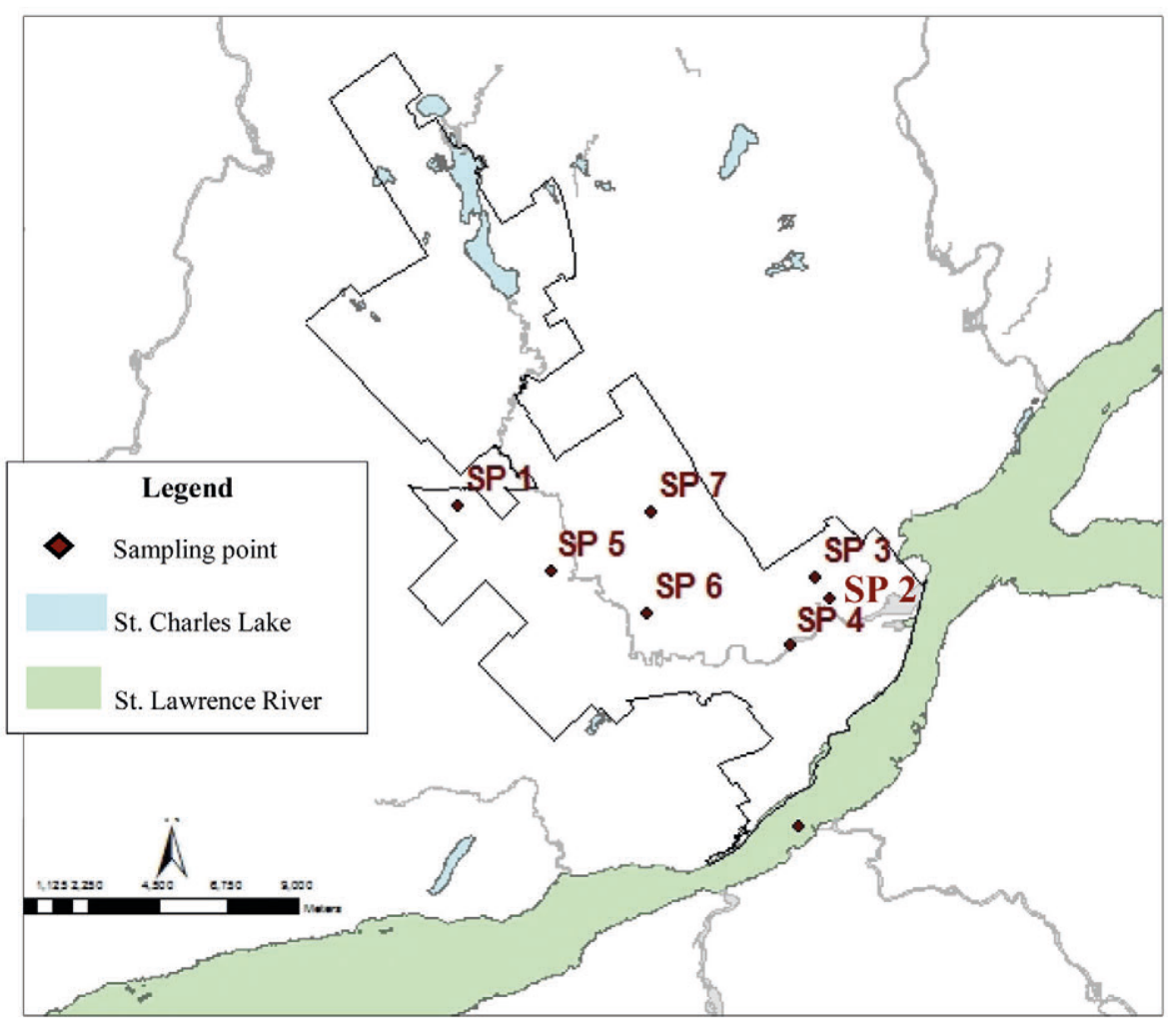

Figure 3:

Sampling stations in a Quebec City DN

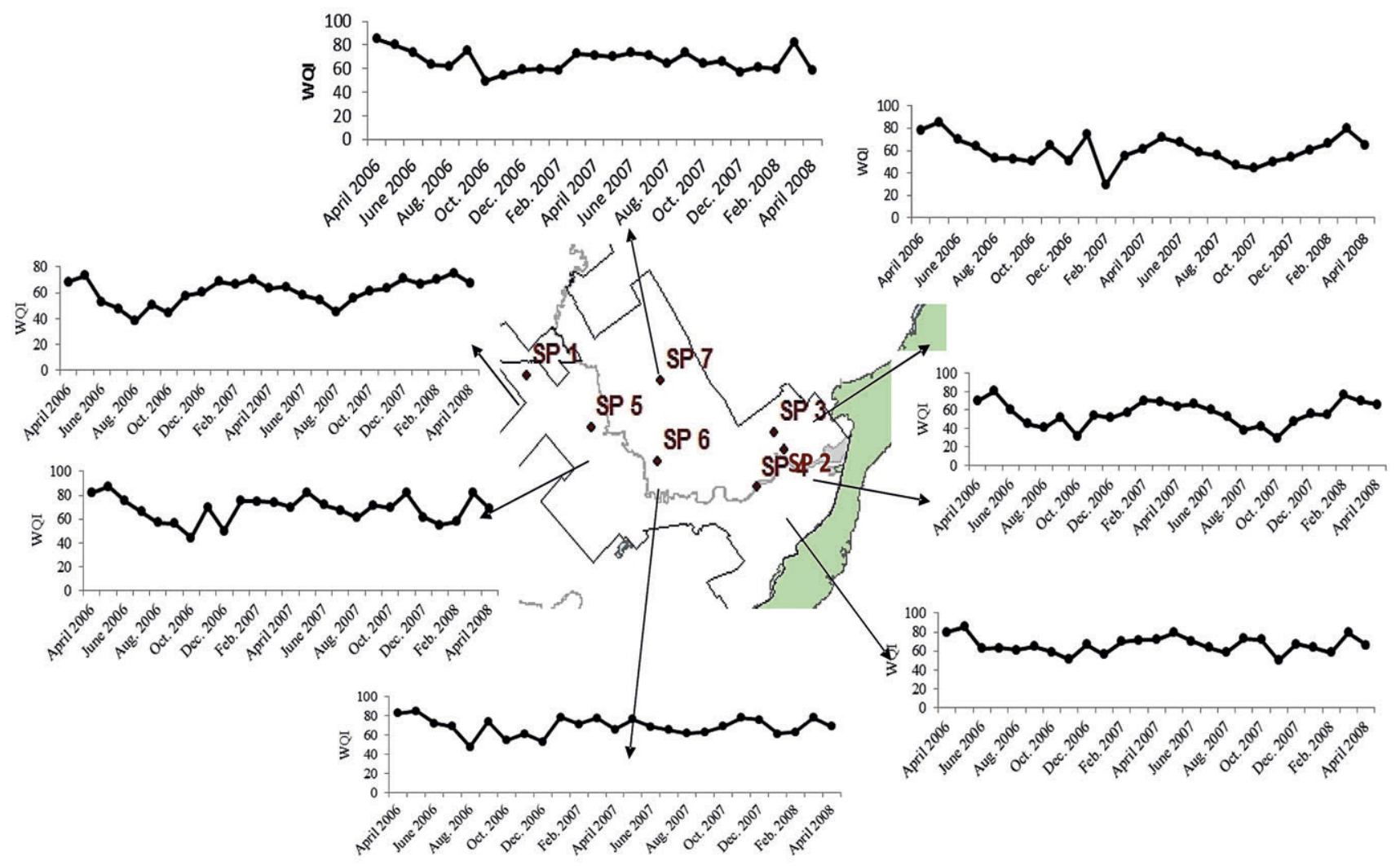

Figure 4:

Monthly variation of water quality index at 7 sampling stations 
December) and starts improving in winter. Sampling point SP2, supplied by re-chlorinated water from a tank located in the distribution system, shows comparatively lower water quality than other points. The higher level of FRC (due to re-chlorination in the tank) could be one of the main reasons for the relatively lower water quality at SP2. The higher residence time of water in the system at this point, due to the residence time in the tank and the location of SP2 at an extremity of the system, could also explain the higher TTHM levels which resulted in lower water quality.

\section{Spatial variability of WQI}

It is not feasible to perform water quality assessment at every node of a DN. Monitoring requires enormous resources and labour. For small municipalities, the availability of data is thus even more limited. In this situation spatial interpolation can be a useful tool to observe spatial variability.

Spatial interpolation determines a constituent value at a place where it is not measured but can be interpolated based on measurements taken at other places. This can be valuable to map WQI
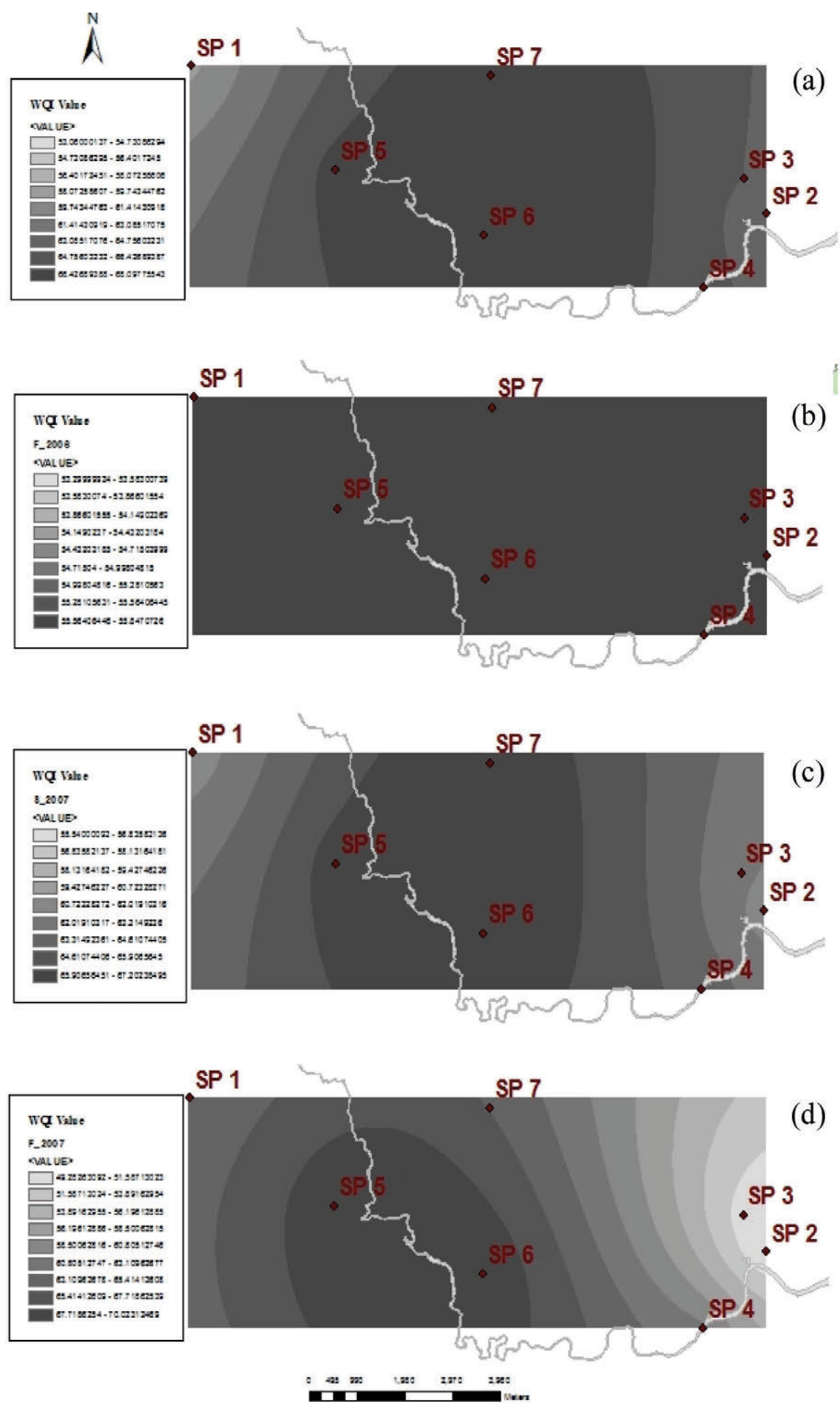

Figure 5:

Water quality index spatial variation using kriging in ArcMap (a) summer 2006, (b) autumn 2006, (c) summer 2007, and (d) autumn 2007 
for a DN, especially for small municipalities. Kriging is an advanced geo-statistical tool that can be used for spatial interpolation (Bayraktar and Turalioglu, 2005). It can be applied after investigating the interaction of spatial behaviour using $z$ values, and generates a map for an area using some known values. Details of the kriging method can be found elsewhere (Murphy et al., 2010). A number of studies related to water quality at source (Garreta et al., 2010; Murphy et al., 2010) and ground water (Baalousha, 2010; Spruill and Candela, 1990) using kriging have been published. Studies have also been conducted to interpolate pressure and flow at DNs (Bogdan and Studzinski, 2007). Therefore, kriging was applied in this study to observe the spatial variability of water quality using ArcMap 10.0.

As previously observed, the water quality index is generally lower during summer and autumn; therefore, only results for these seasons were be analysed to study the spatial variation of the index. The monthly results from May to August were combined using simplistic averages to represent the summer season, while September to December were combined to represent autumn. Figure 5 presents the spatial variation for summer-2006, autumn-2006, summer-2007, and autumn-2007. The water quality ranges from 'marginal' (WQI value: $21-50$ ) to 'fair' (WQI value: $51-70$ ). Much spatial variation can be seen for autumn-2007, ranging from 'marginal' to 'fair'. Autumn-2006 shows less spatial variation (WQI: 55.85-55.86) as the water quality was 'fair' throughout. The water quality is better in summer-2007 compared to summer-2006. For most cases, the central region of spatial analysis (Fig. 5) shows better water quality compared to the peripheral regions.

The water quality in distribution depends on the flow rate, flow direction, and stagnation time. Higher flow rates can result in more dilution and lower contaminant concentrations. Higher stagnation time can also favour FRC decay and DBP generation. Stagnation can also result in low FRC and high DBP levels. Avoiding stagnation zones can thus contribute to improving water quality (Coelho et al., 2003). Introducing re-chlorination or booster points and a minimum chlorine dosage application can be a solution to improve water quality. This will maintain minimum levels of free residual chlorine which will make the system safe in spite of further contamination and result in fewer DBPs. For example, installing new re-chlorination stations near SP2 and SP3, and optimizing the chlorine dosages in these stations, can improve the water quality, especially during autumn and summer. Further optimization studies are recommended in this regard.

\section{Comparison with other models}

Most of the WQI formulations encountered in the literature are rigid and not applicable to alternative parameters. Therefore, average, weighted average, and conventional CCME WQI were compared with the modified CCME WQI proposed herein. Figure 6 shows the comparison between these assessment formulations. The modified CCME WQI proves to be comparable with the average and weighted average formula, and with higher $R^{2}$ values. Conventional CCME WQI shows less sensitivity as most of the results give the same index value. The modified CCME WQI delivers the basic outcome of the original CCME WQI, but is more specific to DBP rules. The sensitivity can be assessed by adding other parameters to the index.

\section{Sensitivity after adding other DBPs}

Parameters are added to the modified CCME WQI to observe the variation in sensitivity after considering further DBPs. BDCM, DBCM, and DCAA are added step by step in the modified aggregation function and the WQIs are called, respectively, modified CCME WQI Level 2, Level 3, and Level 4. For example, in modified CCME WQI Level 2, turbidity, FRC, TTHM, and BDCM are considered. DBCM is added with turbidity, FRC, TTHM, and BDCM for modified CCME WQI Level 3. Level 4 has DCAA in addition to the parameters considered in Level 3. It should be noted that additional parameters were selected randomly for the sole purpose of showing the effect of parameter addition on sensitivity. Simplistic sub-index functions are used in this regard. MCLGs for BDCM and DCAA are 0. Complete failure (SI value $=1$ ) is assumed if there is any detection of those parameters. For DBCM, simplistic linear functions are assumed with the MCLG of $6 \mu \mathrm{g} / \mathrm{L}$ (USEPA, 2006).

Figure $7 \mathrm{a}$ shows the variation in turbidity for modified CCME WQI, and modified CCME WQI Level 2, Level 3 , and Level 4 . Water quality shows a decreasing trend with increasing turbidity. Levels 2 and 3 give similar results. The water quality showed more degraded value in Level 4 . The parameter weights are $0.78,0.81$, and 0.74 for BDCM, DBCM, and DCAA respectively. The figure says adding parameter decreases the sensitivity of the formulation.

Water quality change from changing FRC (Fig. 7b) shows a quite different graphical trend to that of turbidity. Water quality is higher when FRC is between 0.3 and $0.8 \mathrm{mg} / \mathrm{L}$. Water quality shows less variability with addition of a new parameter.

Figure $7 \mathrm{c}$ shows decreasing water quality with increasing TTHM. The sensitivity of the index to TTHM is much higher than to turbidity, as TTHM has a higher calculated weight. The results for Levels 2, 3, and 4 indicate similar sensitivity observations as for FRC and turbidity. The sensitivity analysis thus indicates that addition of unnecessary parameters decreases the sensitivity of the index. Therefore, careful parameter selection is recommended.

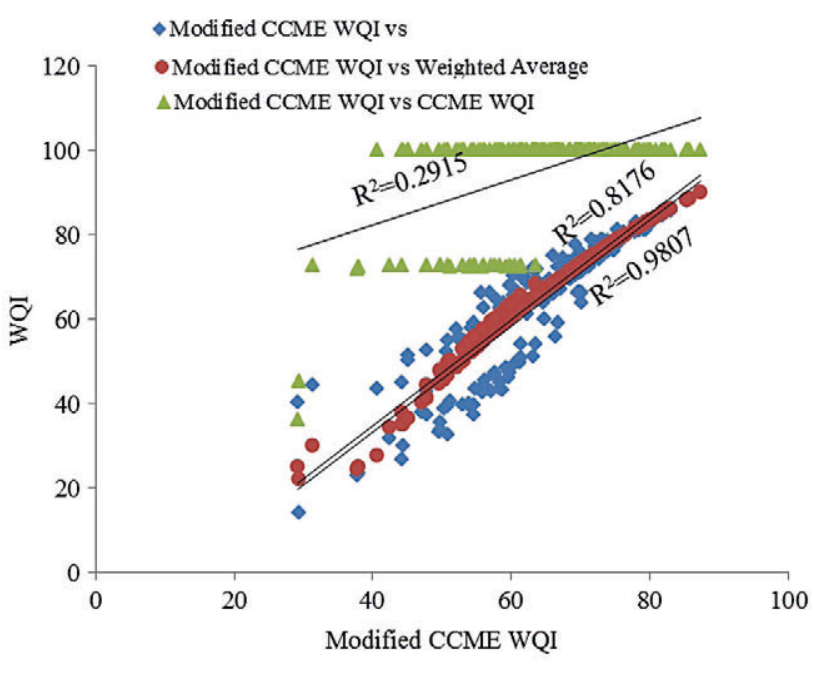

Figure 6:

Comparison of various WQIs 


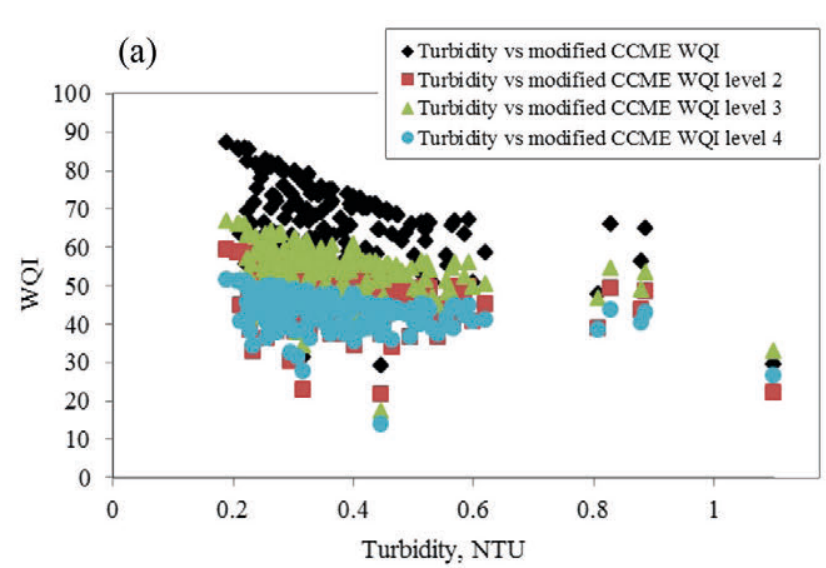

(b)

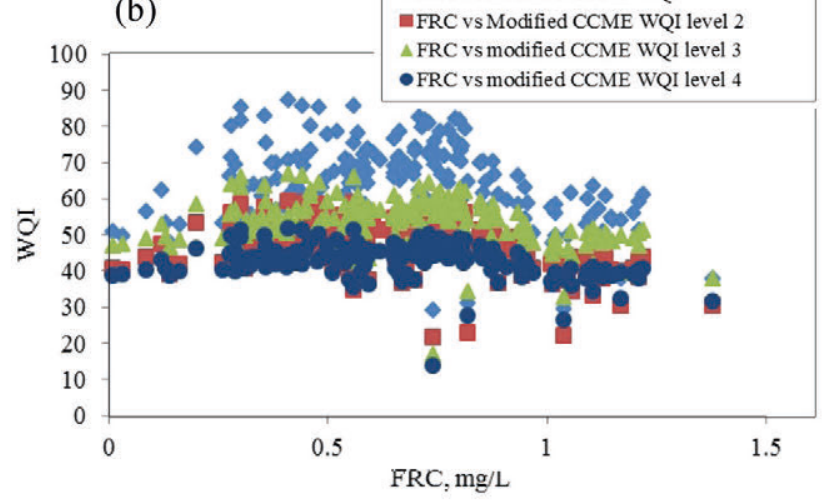

(c)

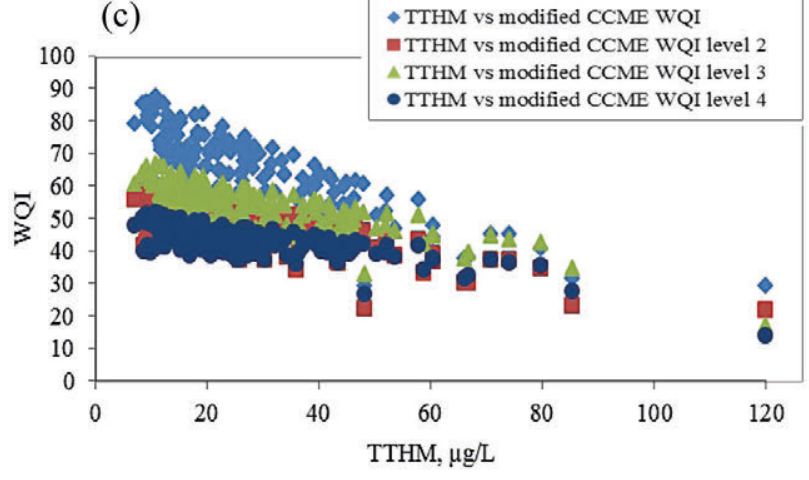

Figure 7:

Sensitivity observation after parameter addition for (a) turbidity, (b) FRC and (c) TTHM

Disinfection is essential to ensure microbiological water quality, but also degrades chemical water quality through the creation of potentially harmful disinfection by-products (DBPs). Therefore, the US EPA has established Stage 1 and Stage 2 Rules to control DBP exposure effects on human health. An index to assess the water quality in terms of compliance with DBP rules has been proposed in this paper. The index is based on CCME WQI, but with slight modification to assign parameter weights following DBP rules. Parameters are selected based on Stage 1 and Stage 2 Rules, with one additional parameter, i.e., turbidity, which is intended to indirectly represent microbial water quality. A scoring method with AHP is proposed to assign parameter weights based on Stage 1 and 2 Rules. The proposed index has flexibility, e.g. enabling the use of flexible parameter conversion functions or any number of parameters. These flexibilities make it suitable for small communities where severe resource limitations exist. Intelligent decision making is possible with this tool as it can show spatial variation by addition of a geo-statistical method.

A case study was performed in a DN in Québec, Canada. The DN used was not a small DN, but was used as a case study as a large dataset was available to assess the water quality. Considering the constraints of smaller municipalities, only turbidity, FRC, and TTHM were considered to assess the water quality. The monthly water quality assessment shows that the best water quality occurs from January to April. The water quality starts degrading from May and reaches its worst levels from September to October. Higher temperatures increase the rate of reaction between FRC and organic matter, which results in less FRC and more DBPs. Water quality starts improving from November and is best in winter. Spatial analysis using the geo-statistical method of kriging was done to estimate water quality in regions without sampling stations. The spatial analysis can identify the locations in the $\mathrm{DN}$ with relatively lower water quality, where decision makers need to concentrate their efforts. Assigning booster stations with adequate dosage is one of the possible options to deal with this situation. Further studies on optimization to improve water quality through booster stations are required.

\section{ACKNOWLEDGMENTS}

Authors thankfully acknowledge the financial support of the second and third authors by the Natural Sciences and Engineering Research Council (NSERC). We would also like to thank RES'EAU-WaterNet, a network group to support small and rural community water management in North America, for motivating this research. Lastly, we would like to thank NSERC once again for providing the Alexander Graham Bell Canada Graduate Scholarship (CGSD2) to the first author.

\section{REFERENCES}

BAALOUSHA H (2010) Assessment of a groundwater quality monitoring network using vulnerability mapping and geostatistics: A case study from Heretaunga Plains New Zealand. Agric. Water Manage. 97 (2) 240-246. http://dx.doi.org/10.1016/j. agwat.2009.09.013

BAYRAKTAR H and TURALIOGLU FS (2005) A Kriging-based approach for locating a sampling site-in the assessment of air quality. Stoch. Environ. Res. Risk Assess. 19 (4) 301-305. http:// dx.doi.org/10.1007/s00477-005-0234-8

BOGDAN L and STUDZINSKI J (2007) Modeling of water pressure distribution in water nets using the kriging algorithm. $5^{\text {th }}$ International Industrial Simulation Conference, 11-13 June 2007, Delft Netherlands 52-56.

BOYACIOGLU H (2007) Development of a water quality index based on a European classification scheme. Water SA 33 (1) 101-106.

CCME (CANADIAN COUNCIL OF MINISTRIES OF THE ENVIRONMENT) (2001) Canadian water quality guidelines for the protection of aquatic life: Canadian water quality index 10 technical report. CCME, Winnipeg.

CHARISIADIS P, ANDRA SS, MAKRIS KC, CHRISTOPHI CA, SKARLATOS D, VAMVAKOUSIS V, KARGAKI S and STEPHANOU EG (2015) Spatial and seasonal variability of tap water disinfection by-products within distribution pipe networks. Sci. Total Environ. 506-507 26-35. http://dx.doi.org/10.1016/j. scitotenv.2014.10.071

CHUNG E and LEE K (2009) Prioritization of water management for sustainability using hydrologic simulation model and multicriteria 
decision making techniques. J. Environ. Manage. 90 (3) 1502-1511. http://dx.doi.org/10.1016/j.jenvman.2008.10.008

COELHO ST, JAMES S, SUNNA N, JAISH AA and CHATIIA J (2003) Controlling water quality in intermittent supply systems. Water Sci. Technol. Water Supply 3 (1-2) 119-125.

DUNNETTE DA (1979) A geographically viable water quality index used in Oregon. J. Water Pollut. Control Fed. 51 53-61.

ESPEJO L, KRETSCHMER N, OYARZÚN J, MEZA F, NÚÑEZ J, MATURANA H, SOTO G, OYARZO P, GARRIDO M, SUCKEL F, AMEZAGA J and OYARZÚN R (2012) Application of water quality indices and analysis of the surface water quality monitoring network in semiarid North-Central Chile. Environ. Monit. Assess. 184 (9) 5571-5588. http://dx.doi.org/10.1007/s10661-011-2363-5

GARRETA V, MONESTIEZ P and VER HOEF JM (2010) Spatial modelling and prediction on river networks: Up model down model or hybrid? Environmetrics 21 (5) 439-456.

HEALTH CANADA (2009) Guidelines for Canadian Drinking Water Quality. Ottawa, Ontario.

HURLEY T, SADIQ R and MAZUMDER A (2012) Adaptation and evaluation of the Canadian Council of Ministers of the Environment Water Quality Index (CCME WQI) for use as an effective tool to characterize drinking source water quality. Water Res. 46 (11) 3544-3552. http://dx.doi.org/10.1016/j. watres.2012.03.061

ISLAM N, SADIQ R and RODRIGUEZ M J (2013) Optimizing booster chlorination in water distribution networks: a water quality index approach. Environ. Monit. Assess. 185 (10) 8045-8050. http:// dx.doi.org/10.1007/s10661-013-3153-Z

ISLAM N, SADIQ R, RODRIGUEZ MJ and FRANCISQUE A (2011) Reviewing source water protection strategies: A conceptual model for water quality assessment. Environ. Rev. 19 68-105. http://dx.doi. org/10.1139/a11-001

KHAN F, HUSAIN T and LUMB A (2003) Water quality evaluation and trend analysis in selected watersheds of the Atlantic region of Canada. Environ. Monit. Assess. 88 (1) 221-248. http://dx.doi. org/10.1023/A:1025573108513

LEGAY C, RODRIGUEZ MJ, MIRANDA-MORENO L, SÉRODES J-B and LEVALLOIS P (2011) Multi-level modelling of chlorination byproduct presence in drinking water distribution systems for human exposure assessment purposes. Environ. Monit. Assess. 178 (1-4) 507-524. http://dx.doi.org/10.1007/s10661-010-1709-8

LIOU S LO S and WANG S (2004) A generalized water quality index for Taiwan. Environ. Monit. Assess. 96 (1-3) 35-52. http://dx.doi. org/10.1023/B:EMAS.0000031715.83752.a1

LUMB A, HALLIWELL D and SHARMA T (2006) Application of CCME Water Quality Index to monitor water quality: A case study of the Mackenzie River basin Canada. Environ. Monit. Assess. 113 (1) 411-429. http://dx.doi.org/10.1007/s10661-005-9092-6

MURPHY RR, CURRIERO FC and BALL WP (2010) Comparison of Spatial Interpolation Methods for Water Quality Evaluation in the Chesapeake Bay. J. Environ. Eng. 136 (2) 160-171. http://dx.doi. org/10.1061/(ASCE)EE.1943-7870.0000121

PESCE SF and WUNDERLIN D A (2000) Use of water quality indices to verify the impact of Cordoba city (Argentina) on Suquia River. Water Res. 34 (11) 2915-2926. http://dx.doi.org/10.1016/ S0043-1354(00)00036-1

RICHARDSON SD, PLEWA MJ, WAGNER ED, SCHOENY R and
DEMARINI DM (2007) Occurence genotoxicity and carcinogenicity of regulated and emerging disinfection by-products in drinking water: A review and roadmap for research. Mutat. Res. 636 178-242. http://dx.doi.org/10.1016/j.mrrev.2007.09.001

ROOK JJ (1974) Formation of haloforms during chlorination of natural waters. Water Treat. Examination. 23 (2) 234-243.

SAATY T (1977) A scaling method for priorities in hierarchical structures. J. Math. Psychol. 15 57-68. http://dx.doi. org/10.1016/0022-2496(77)90033-5

SADIQ R and RODRIGUEZ MJ (2004) Fuzzy synthetic evaluation of disinfection by-products--a risk-based indexing system. J. Environ. Manage. 73 (1) 1-13. http://dx.doi.org/10.1016/j. jenvman.2004.04.014

SAID A, STEVENS DK and SEHLKE G (2004) An innovative index for evaluating water quality in streams. Environ. Manage. 34 (4) 406-414. http://dx.doi.org/10.1007/s00267-004-0210-y

SPRUILL TB and CANDELA L (1990) Two approaches to design of monitoring networks. Ground Water 28 (3) 430-442. http://dx.doi. org/10.1111/j.1745-6584.1990.tb02272.x

SWAMEE PK and TYAGI A (2007) Improved method for aggregation of water quality subindices. J. Environ. Eng. 133 (2) 220-225. http:// dx.doi.org/10.1061/(ASCE)0733-9372(2007)133:2(220)

TESFAMARIAM S and SADIQ R (2006) Risk-based environmental decision-making using fuzzy analytic hierarchy process (F-AHP). Stoch. Environ. Res. Risk Assess. 21 (1) 35-50. http://dx.doi. org/10.1007/s00477-006-0042-9

USEPA (UNITED STATES ENVIRONMENTAL PROTECTION AGENCY) (1995a) Measurement of Purgeable Organic Compounds in Water by Capillary Column Gas Chromatography/Mass Spectrometry. United States of America 47. USEPA, Washington D.C.

USEPA (UNITED STATES ENVIRONMENTAL PROTECTION AGENCY) (1995b) Determination of Haloacetic Acids in Drinking Water by Liquid Liquid Extraction and Gas Chromatography with Electron Capture Detection. Cincinnati Ohio United States of America. USEPA, Washington D.C.

USEPA (UNITED STATES ENVIRONMENTAL PROTECTION AGENCY) (2005) Economic Analysis for the Final Stage 2 Disinfectants and Disinfection Byproducts Rule. 815-R-05-010. USEPA, Washington D.C.

USEPA (UNITED STATES ENVIRONMENTAL PROTECTION AGENCY) (2006) Comprehensive Disinfectants and Disinfection Byproducts Rules (Stage 1 and Stage 2): Quick Reference Guide Overview of the Rules 2-5. USEPA, Washington D.C.

USEPA (UNITED STATES ENVIRONMENTAL PROTECTION AGENCY) (2007) Simultaneous Compliance Guidance Manual for the Long Term 2 and Stage 2 DBP Rules. EPA 815-R-07-017. USEPA, Washington D.C.

USEPA (UNITED STATES ENVIRONMENTAL PROTECTION AGENCY) (2009) Drinking Water Contaminants. URL: http://waterepagov/drink/contaminants/indexcfm. USEPA, Washington D.C.

USEPA (UNITED STATES ENVIRONMENTAL PROTECTION AGENCY) (2010) Comprehensive Disinfectants and Disinfection Byproducts Rules (Stage 1 and Stage 2): Quick Reference Guide. USEPA, Washington D.C.

USEPA (UNITED STATES ENVIRONMENTAL PROTECTION AGENCY) (2013) Integrated Risk Information System (IRIS). URL: http://wwwepagov/IRIS/. USEPA, Washington D.C. 


\section{APPENDIX}

\section{List of abbreviations}

\begin{tabular}{|c|c|}
\hline AHP & Analytic hierarchy process \\
\hline BDCM & Bromodichloromethane \\
\hline CCME WQI & Canadian Council of Ministries of the \\
\hline & Environment Water Quality Index \\
\hline DBAA & Dibromoacetic acid \\
\hline DBCM & Dibromochloromethane \\
\hline DBP rules & $\begin{array}{l}\text { Stage } 1 \text { and Stage } 2 \text { Disinfection ByProducts } \\
\text { Rules }\end{array}$ \\
\hline DBPs & Disinfection by-products \\
\hline DCAA & Dichloroacetic acid \\
\hline $\mathrm{DN}$ & Distribution network \\
\hline FRC & Free residual chlorine \\
\hline HAA5 & Five species of haloacetic acid \\
\hline HAAs & Haloacetic acids \\
\hline MBAA & Monobromoacetic acid \\
\hline MCAA & Monochloroacetic acid \\
\hline MCLG & Maximum contaminant level goals \\
\hline MRDL & Maximum residual disinfectant level \\
\hline TCAA & Trichloroacetic acid \\
\hline THMs & Trihalomethanes \\
\hline ТTHM & Total trihalomethane \\
\hline US EPA & US Environmental Protection Agency \\
\hline WQI & Water quality index \\
\hline
\end{tabular}

